\title{
Erratum to: Effects of Forming Processes on the Microstructure and Solderability of Sn-3.5Ag Eutectic Solder Ribbons as well as the Mechanical Properties of Solder Joints
}

\author{
SHENGFA LIU, ${ }^{1}$ ZHEBING HU, ${ }^{1,3}$ JIERAN XIONG ${ }^{2}$ GUANGHUA TAN, ${ }^{1}$ \\ WENYONG XIONG ${ }^{1}$ CHEN CHEN, ${ }^{1}$ and SHANGYU HUANG ${ }^{1}$ \\ 1.-School of Materials Science and Engineering, Wuhan University of Technology, \\ Wuhan 430070, China. 2.-Shanwei Bolin Electronic Package Material Co., Ltd., Shanwei 516600, \\ China. 3.—e-mail: huzhebing_123@163.com
}

\section{Erratum to: Journal of ELECTRONIC MATERIALS \\ DOI: $10.1007 / \mathbf{s 1 1 6 6 4 - 0 1 7 - 5 6 7 2 - 9}$}

In the third paragraph of "Introduction" in the original article, the term $\mathrm{Ag}_{3} \mathrm{Snm}$ should be $\mathrm{Ag}_{3} \mathrm{Sn}$.

The original article has been updated. 